\title{
Fructose, but Not Dextrose, Induces Leukocyte Adherence to the Mesenteric Venule of the Rat by Oxidative Stress
}

\author{
LEONE F. MATTIOLI, NAOMI B. HOLLOWAY, JAMES H. THOMAS, AND JOHN G. WOOD
}

Departments of Pediatrics [L.F.M.], Surgery [N.B.H., J.H.T., J.G.W.], and Molecular and Integrative Physiology [J.G.W.], University of Kansas Medical Center, Kansas City, Kansas 66160

\begin{abstract}
Recent evidence indicates that fructose is a proinflammatory molecule. Oral fructose induces serum and kidney inflammatory intercellular adhesion molecule-1 (ICAM-1) in rats. Fructose also induces ICAM-1 expression in human aortic endothelial cells (HAEC) and monocyte chemoattractant protein-1 in proximal tubular renal cells. It is not known whether fructose may directly promote inflammation on the intestinal microcirculation. Accordingly, using intravital microscopy we studied the effect of topical fructose and dextrose on leukocyte adherence to the mesenteric venule of the rat. Leukocyte adherence was determined during a control period and after fructose was added to the mesentery, in the presence or absence of the NO donor spermine NONO-ate (SNO), and after i.v. injection of the antioxidant lipoic acid (LA). In separate experiments, we examined the effect of topical dextrose on leukocyte adherence to the mesenteric venule. Venular shear rate was calculated. Fructose, but not dextrose, induced significant inflammation independent of shear rate. This effect was completely blocked by SNO and LA, suggesting that fructose induces inflammation via reactive oxygen species (ROS) generation. These results suggest that fructose present in formulas may adversely affect the intestinal microcirculation of premature infants and potentially contribute to the pathogenesis of necrotizing enterocolitis (NEC). (Pediatr Res 67: 352-356, 2010)
\end{abstract}

$\mathrm{C}$ onsiderable evidence indicates that necrotizing enterocolitis (NEC), a life-threatening complication of very low birth weight infants, occurs more frequently in infants fed formulas than in those fed human breast milk $(1,2)$. The protective effect of human breast milk can be observed even when infants are fed human breast milk and formula in equal proportions (3). Although the pathogenesis of NEC is complex, inflammation of the intestinal mucosa plays a significant role in perforation of the intestinal mucosa (4). The protective effects of human milk include, among others, its antiinflammatory properties (5). To the best of our knowledge, the possible role of fructose in the pathogenesis of NEC has not been explored. Fructose is only present in formulas as sucrose or high fructose corn syrup. Recent evidence indicates that fructose is a potent pro-inflammatory molecule. Fructose when fed to rats in physiologic concentrations increases serum intercellular adhesion molecule (ICAM-1) concentration and also induces ICAM-1 expression in the kidney and in HAEC

Received July 30, 2009; accepted November 20, 2009.

Correspondence: Leone F. Mattioli, M.D., Division of Pediatric Cardiology, Department of Pediatrics, University of Kansas Medical Center, Kansas City, KS, 66160; e-mail: lmattiol@kumc.edu

Supported by the Pediatric Endowment Research Fund and the Department of Surgery Research Fund. by reducing NO, a potent anti-inflammatory molecule (6). In addition, fructose induces monocyte chemo-attractant protein in human renal proximal tubular cells (7) and promotes activation of antioxidant enzymes (8).

To the best of our knowledge, the effect of fructose on the intestinal microcirculation has not been explored. Accordingly, using intravital microscopy, we sought to determine whether fructose may cause inflammation as expressed by increased leukocyte adherence to the vascular endothelium of the mesenteric venule of the rat and if reactive oxygen species (ROS) generation may be involved in this response. We also tested the effect of dextrose on leukocyte adherence in the mesenteric microcirculation.

\section{METHODS}

All procedures involved in this study were approved by the Institutional Animal Care and Use Committee (IACUC) of the University of Kansas. Male adult Sprague-Dawley rats, weighing 200-275 g, were anesthetized with sodium pentobarbital ( $50 \mathrm{mg} / \mathrm{kg}$ intramuscularly). The animal's body temperature was maintained at $36-37^{\circ} \mathrm{C}$ via a homeothermic blanket system connected to an intrarectal temperature probe (Harvard Apparatus). Polyethylene cannulas (PE-50) were inserted into a jugular vein and carotid artery, and a tracheotomy was performed, with a PE-240 then inserted into the trachea. Intra-arterial blood pressure was measured throughout the experiment via the carotid artery cannula connected to a digital blood pressure monitor (MicroMed, Louisville, KY). The animals spontaneously breathed room air via the tracheotomy tube throughout the experiments.

An abdominal incision $\left(\sim 1.5^{\prime \prime}\right.$ long $)$ was made along the midline, and a loop of small intestine was carefully exteriorized. The rat was placed on a Plexiglas tray, and the small intestine was arranged so that a section of mesentery was positioned over a glass coverslip in the bottom of the tray. This arrangement allowed solutions [i.e. saline, fructose, dextrose, and spermine NONO-ate (SNO)] to be added topically directly on the surface of the section of the exposed mesentery. The tray was then placed on the stage of a Zeiss Axiovert inverted microscope to view the mesenteric microcirculation $(40 \times$ objective). Images of mesenteric venules were continuously recorded throughout experiments on a Sony mini-digital recorder using a Panasonic video camera with a time-date generator.

Unbranched mesenteric venules, $20-40 \mu \mathrm{m}$ in diameter and at least 100 $\mu \mathrm{m}$ in length, were chosen to study leukocyte-endothelial cell adhesive interactions, if $\leq 3$ adherent leukocytes were present during control periods, and the venule had no adjacent lymphatic vessels (9). Venule diameter was measured using a video caliper (Microcirculation Research Institute, College Station, TX). An optical Doppler velocimeter (Microcirculation Research Institute) was used to measure center line red blood cell velocity. Average red blood cell velocity was calculated as center line velocity/1.6. Wall shear rate, the tangential force generated at the vessel inner wall by movement of blood, was calculated as $8 \times$ (average red blood cell velocity/venule diameter). The

Abbreviations: HAEC, human aortic endothelial cells; HFCS, high fructose corn syrup; ICAM-1, intercellular adhesion molecule-1; LA, lipoic acid; NEC, necrotizing enterocolitis; ROS, reactive oxygen species; SNO, spermine NONO-ate 
number of leukocytes per $100 \mu \mathrm{m}$ length, adherent to the mesenteric venule as defined by being stationary for $\geq 30 \mathrm{~s}$ were counted off line at the end of control periods and during the last minute of each intervention. Shear rate was also calculated at the same intervals, as shear rate affects the leukocyteendothelial cell adhesive interactions. Adherent cells were counted by one experienced observer aware of the experimental conditions whose intraobserver reliability was assessed by raw percent agreement.

Fructose and lipoic acid (LA) were purchased from Sigma Chemical Co. Chemical and SNO from Cayman Chemical. SNO was prepared in buffer at $\mathrm{pH} 8.5$.

Experimental protocols. Separate groups of animals were used for each experimental protocol.

Effect of fructose on leukocyte adherence ( $\mathrm{n}=5$ animals). In each animal, after a 20-min control period in which the mesentery was superfused with saline, $1 \mathrm{~mL}$ of fructose in increasing isosmolar concentrations of 1 $\mathrm{mg} / \mathrm{dL}(0.05 \mathrm{mM}), 10 \mathrm{mg} / \mathrm{dL}(0.5 \mathrm{mM})$, and $100 \mathrm{mg} / \mathrm{dL}(5.5 \mathrm{mM})$ was then added topically to the mesentery. Each dose was added in equal volumes 3 times at 10 min apart. The number of adherent leukocytes within the mesenteric venule and venular shear rate were determined at the end of the control period and during the last min of each intervention.

Effect of dextrose on leukocyte adherence ( $\mathrm{n}=5$ animals). In each animal, after a 20-min control period in which the mesentery was superfused with saline, $1 \mathrm{~mL}$ of dextrose in increasing isosmolar concentrations of 1 $\mathrm{mg} / \mathrm{dL}(0.05 \mathrm{mM}), 10 \mathrm{mg} / \mathrm{dL}(0.5 \mathrm{mM})$, and $100 \mathrm{mg} / \mathrm{dL}(5.5 \mathrm{mM})$ was then added topically to the mesentery. Each dose was added in equal volumes 3 times at $10 \mathrm{~min}$ apart. The number of adherent leukocytes within the mesenteric venule and venular shear rate were determined at the end of the control period and during the last min of each intervention.

Effect of superfusion of the NO donor SNO $(100 \mu M)$ on fructoseinduced leukocyte adherence $(\mathrm{n}=6$ animals). In each animal, after a 10-min control period, SNO $(100 \mu \mathrm{M})(10)$ was added topically to the mesentery and after $20 \mathrm{~min}, 1 \mathrm{~mL}$ of SNO plus $100 \mathrm{mg} / \mathrm{dL}(5.5 \mathrm{mM})$ fructose was added 3 times at 10 min apart. The number of adherent leukocytes within the mesenteric venule and venular shear rate were determined at the end of the control period and during the last min of each intervention.

Effect of LA (2 mg/kg i.v.) on fructose-induced leukocyte adherence $(\mathrm{n}=$ 6 animals). In each animal, after a 10-min control period, $2 \mathrm{~mL}$ of LA (2 $\mathrm{mg} / \mathrm{kg}$ ) (10) were given i.v. as a bolus via the jugular vein cannula. After 20 min, $1 \mathrm{~mL}$ of $100 \mathrm{mg} / \mathrm{dL}(5.5 \mathrm{mM})$ fructose was added to the superfusate 3 times at $10 \mathrm{~min}$ apart. At $40 \mathrm{~min}$, a 1 - $\mathrm{mL}$ boost of LA was given i.v. The number of adherent leukocytes within the mesenteric venule and venular shear rate were determined at the end of the control period and during the last min of each intervention.

Data analysis. Leukocyte adherence and venular shear rate were measured in a single venule from each rat of all experimental groups. Values represent the average number of adherent leukocytes (means \pm SEM) determined during the last minute of the control period and of each intervention for all animals studied. The effects of fructose on leukocyte adherence and shear rate were compared with control values. The effects of SNO and LA were compared with their respective control values. Comparison within and among groups were analyzed by the one-tailed $t$ test for paired samples. A $p<0.05$ was considered to indicate a statistically significant difference.

\section{RESULTS}

Effect of fructose on leukocyte adherence. Figure 1 shows representative images of a mesenteric venule from one experiment. The black dots are part of the optical Doppler velocimeter used to measure center line red blood cell velocity. Panel $A$ shows an image from a control period with one adherent leukocyte (indicated by a black arrow). Panel $B$ shows a marked increase in the number of adherent leukocytes after $100 \mathrm{mg} / \mathrm{dL}(5.5 \mathrm{mM})$ fructose was added topically to the mesentery. Fructose induced statistically significant increases in leukocyte adherence at concentrations of $1 \mathrm{mg} / \mathrm{dL}, 10$ $\mathrm{mg} / \mathrm{dL}, 100 \mathrm{mg} / \mathrm{dL}(0.05,0.5$, and $5.5 \mathrm{mM}$, respectively) when compared with control values with all $p<0.05$ (Fig. 2 ). This effect of fructose was independent of changes in shear rate as shear rate during fructose was not statistically significant compared with control values: control, $219 \pm 26$ $\mathrm{s}^{-1}$; fructose $1 \mathrm{mg} / \mathrm{dL}(0.05 \mathrm{mM}), 250 \pm 27 \mathrm{~s}^{-1}(p=0.43$
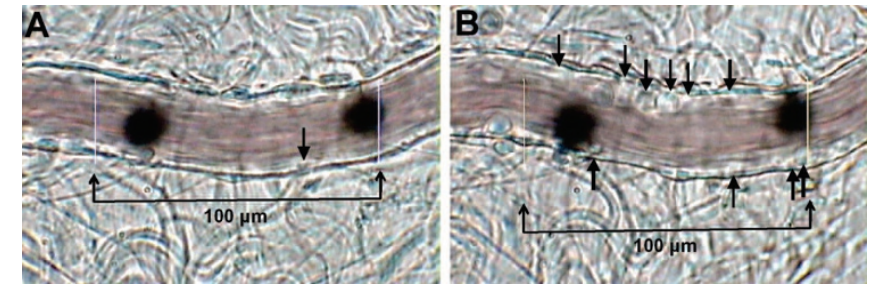

Figure 1. This figure shows representative images of a mesenteric venule from one animal. Panel A shows an image from a control period with one adherent leukocyte (indicated by a black arrow). Panel $B$ shows a marked increase in the number of adherent leukocytes within the same venule after $100 \mathrm{mg} / \mathrm{dL}(5.5 \mathrm{mM})$ fructose was added topically to the mesentery. The white bars are $100 \mu \mathrm{m}$ apart, and the magnification is approximately $1320 \times$. Only the leukocytes within the $100 \mu \mathrm{m}$ length of venule that were counted as adherent are shown by the black arrows. The black dots are part of the optical Doppler velocimeter used to measure center line red blood cell velocity.

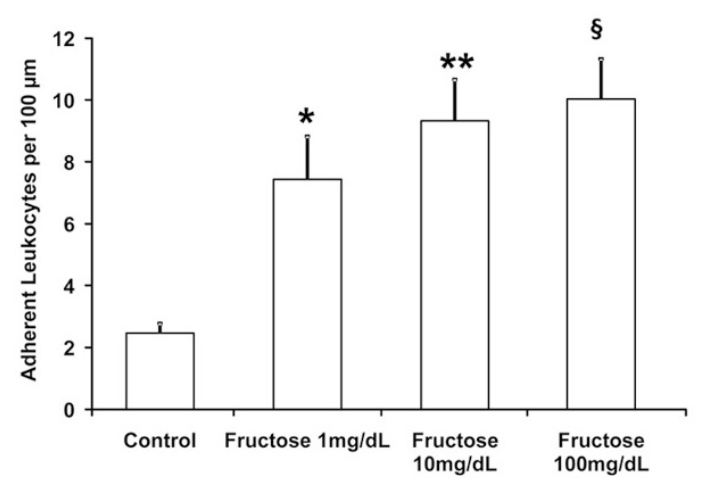

Figure 2. Cumulative results showing dose-related effects of topical fructose on leukocyte adherence in mesenteric venules ( $n=5$ animals). Values represent the average number of adherent leukocytes (means \pm SEM) determined during the last minute of the control period and of each intervention for all animals studied. *indicates $p<0.05$, **indicates $p<0.01$, and §indicates $p<0.001$ vs control respectively.

versus control), $10 \mathrm{mg} / \mathrm{dL}(0.5 \mathrm{mM}), 260 \pm 32 \mathrm{~s}^{-1}(p=$ 0.35 versus control); and $100 \mathrm{mg} / \mathrm{dL}(5.5 \mathrm{mM}), 245 \pm 21$ $\mathrm{s}^{-1}(p=0.46$ versus control).

Effect of dextrose on leukocyte adherence. Topical administration of dextrose at concentrations of $1 \mathrm{mg} / \mathrm{dL}, 10 \mathrm{mg} / \mathrm{dL}$, $100 \mathrm{mg} / \mathrm{dL}(0.05,0.5$, and $5.5 \mathrm{mM}$, respectively) did not result in statistically significant changes in leukocyte adherence compared with control values ( $n=5$ animals): control, $2.6 \pm$ 0.4 per $100 \mu \mathrm{m}$; dextrose $1 \mathrm{mg} / \mathrm{dL}(0.05 \mathrm{mM}), 3.4 \pm 0.9$ per $100 \mu \mathrm{m}(p=0.44$ versus control $) ; 10 \mathrm{mg} / \mathrm{dL}(0.5 \mathrm{mM}), 2.2 \pm$ 0.3 per $100 \mu \mathrm{m}$ ( $p=0.44$ versus control); and $100 \mathrm{mg} / \mathrm{dL}(5.5$ $\mathrm{mM}), 2.6 \pm 0.2$ per $100 \mu \mathrm{m}(p=0.99$ versus control). In addition, dextrose did not produce statistically significant changes in venular shear rate compared with control values: control, $330 \pm 37 \mathrm{~s}^{-1}$; dextrose $1 \mathrm{mg} / \mathrm{dL}(0.05 \mathrm{mM}), 307 \pm$ $32 \mathrm{~s}^{-1}(p=0.65$ versus control $) ; 10 \mathrm{mg} / \mathrm{dL}(0.5 \mathrm{mM}), 331 \pm$ $42 \mathrm{~s}^{-1}(p=0.98$ versus control); and $100 \mathrm{mg} / \mathrm{dL}(5.5 \mathrm{mM})$, $355 \pm 22 \mathrm{~s}^{-1}(p=0.58$ versus control).

Effect of superfusion of the NO donor SNO (100 $\mu M)$ on fructose-induced leukocyte adherence. In Fig. 3, Panel A shows a marked increase in leukocyte adherence when 100 $\mathrm{mg} / \mathrm{dL}(5.5 \mathrm{mM})$ fructose was added topically to the mesentery. Panel $B$, taken from a separate experiment, shows complete inhibition of fructose-induced leukocyte adherence by 


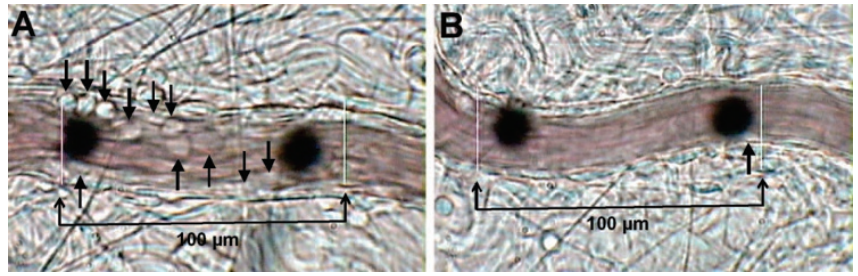

Figure 3. Panel $A$ shows a marked increase in leukocyte adherence when $100 \mathrm{mg} / \mathrm{dL}(5.5 \mathrm{mM})$ fructose was added to the mesentery. Panel $B$, taken from a separate experiment, shows complete inhibition of fructose-induced leukocyte adherence by SNO $(100 \mu \mathrm{M})$. The white bars are $100 \mu \mathrm{m}$ apart, and the magnification is approximately $1320 \times$. Only the leukocytes within the $100 \mu \mathrm{m}$ length of venule that were counted as adherent are shown by the black arrows. The black dots are part of the optical Doppler velocimeter used to measure center line red blood cell velocity.

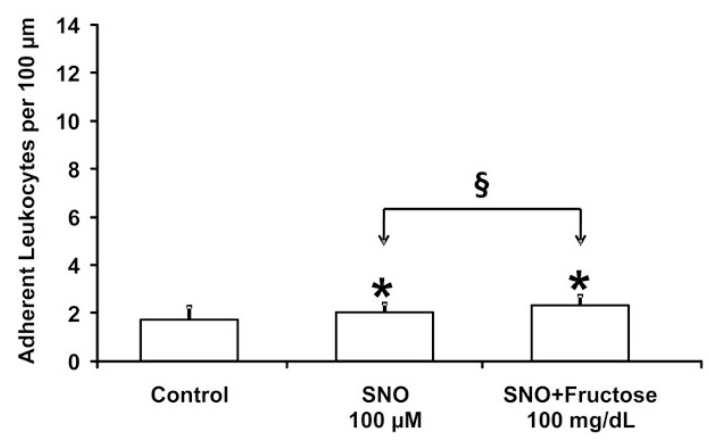

Figure 4. Number of adherent leukocytes with SNO $(100 \mu \mathrm{M})$ plus fructose $100 \mathrm{mg} / \mathrm{dL}(5.5 \mathrm{mM})$ is not significantly different from that of SNO alone and of control ( $n=6$ animals). Values represent the average number of adherent leukocytes (means \pm SEM) determined during the last min of the control period and of each intervention. *indicates $p>0.05$ for SNO alone and SNO plus fructose $v s$ control. §indicates $p>0.05$ for SNO plus fructose $v s$ SNO alone.

SNO $(100 \mu \mathrm{M})$. Figure 4 shows bar graphs of the number of leukocytes adherent to the mesenteric venule at control, after SNO alone $(100 \mu \mathrm{M})$ was added to the superfusate, and after the addition of one $\mathrm{ml}$ of fructose, $100 \mathrm{mg} / \mathrm{dL}(5.5 \mathrm{mM})$, plus SNO. The number of adherent leukocytes after SNO plus fructose were added to the superfusate did not differ from that of control, indicating that SNO completely inhibited fructoseinduced leukocyte adherence. This effect was independent of changes in shear rate as shear rate during SNO plus fructose was not statistically significant compared with control: control, $380 \pm 56 \mathrm{~s}^{-1}$; SNO, $374 \pm 47 \mathrm{~s}^{-1}(p=0.94$ versus control); SNO plus fructose, $332 \pm 49 \mathrm{~s}^{-1}$ ( $p=0.54$ versus control).

Effect of LA (2 mg/kg i.v.) on fructose-induced leukocyte adherence. In Fig. 5, Panel A shows the effect of $100 \mathrm{mg} / \mathrm{dL}$ $(5.5 \mathrm{mM})$ fructose on leukocyte adherence from one experiment, whereas Panel B shows complete inhibition by LA of fructose-induced leukocyte adherence in another animal. Figure 6 shows bar graphs of the number of leukocytes adherent to the mesenteric venule at control, after i.v. injection of LA $(2 \mathrm{mg} / \mathrm{kg})$, and after $1 \mathrm{~mL}$ of fructose, $100 \mathrm{mg} / \mathrm{dL}(5.5 \mathrm{mM})$, was added topically to the mesentery. The number of adherent leukocytes after LA was given i.v. and after fructose was added topically to the mesentery did not differ from that of
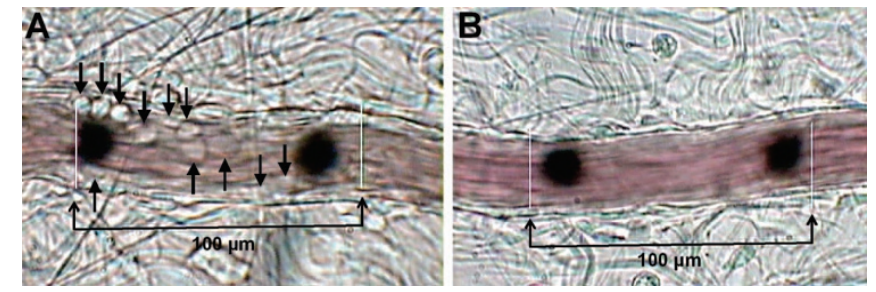

Figure 5. Panel $A$ shows the effect of $100 \mathrm{mg} / \mathrm{dL}(5.5 \mathrm{mM})$ fructose on leukocyte adherence from one experiment, whereas Panel $B$ shows complete inhibition by LA ( $2 \mathrm{mg} / \mathrm{kg}$ i.v.) of fructose-induced leukocyte adherence in another animal. The white bars are $100 \mu \mathrm{m}$ apart, and the magnification is approximately $1320 \times$. Only the leukocytes within the $100 \mu \mathrm{m}$ length of venule that were counted as adherent are shown by the black arrows. The black dots are part of the optical Doppler velocimeter used to measure center line red blood cell velocity.

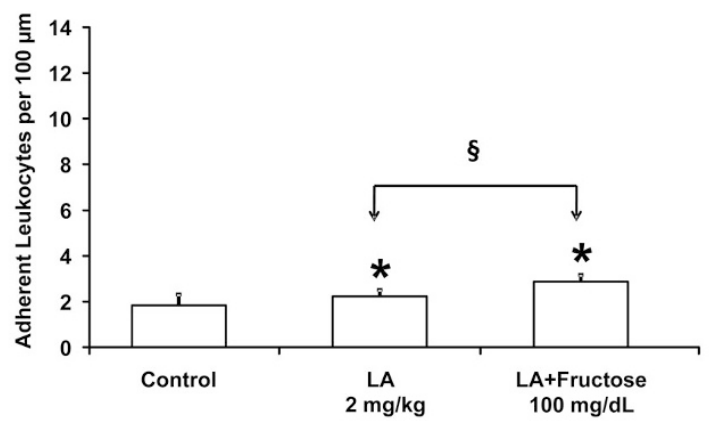

Figure 6. Number of adherent leukocytes with LA plus fructose $100 \mathrm{mg} / \mathrm{dL}$ $(5.5 \mathrm{mM})$ is not significantly different $v s$ LA alone $(2 \mathrm{mg} / \mathrm{kg}$ i.v. $)$ and control ( $n=6$ animals). Values represent the average number of adherent leukocytes (means \pm SEM) determined during the last minute of the control period and of each intervention for all animals studied. *indicates $p>0.05$ for LA alone and LA plus fructose $v s$ control. §indicates $p>0.05$ for LA plus fructose $v s$ LA alone.

control, indicating that LA completely inhibited fructoseinduced leukocyte adherence. The slightly higher shear rate observed after the initial i.v. injection of LA was probably due to bolus effect. However, shear rate after LA plus fructose was not significantly different from at control: control, $283 \pm 31 \mathrm{~s}^{-1}$; LA alone, $352 \pm 22 \mathrm{~s}^{-1}$ ( $p=0.10$ versus control); and LA plus fructose, $284 \pm 27 \mathrm{~s}^{-1}(p=0.98$ versus control).

\section{DISCUSSION}

We used intravital microscopy to study leukocyte endothelial cell adhesive interactions in the mesenteric microcirculation to determine whether fructose may induce inflammation and if so, by which mechanisms. This technique has been extensively used in our laboratory to study the effect of systemic hypoxia on microvascular inflammation in rat mesenteric venules (9-11).

Our study shows for the first time, that fructose, but not dextrose, when superfused over the mesenteric venule of the rat, promotes significant leukocyte adherence to the vascular endothelium, a sign of inflammation. We showed that fructose induced significant leukocyte adherence in the mesenteric microcirculation at concentrations of $0.05,0.5$, and $5 \mathrm{mM}$. The concentrations used in our study are similar to circulating levels achieved in humans after a fructose meal. Serum fruc- 
tose levels have been shown to rise to $0.4 \mathrm{mM}$ (12) and 0.8 $\mathrm{mM}$ within $30 \mathrm{~min}$ (13) after ingestion of fructose. Our results are in agreement of those of Gersch et al. (7) who showed, in rats fed $60 \%$ fructose diets, greater recruitment of monocytes within the kidney compared with rats fed $60 \%$ dextrose or normal diets. Our results are also consistent with those of Glushakova et al. (6) who showed that fructose, even at a dose of $0.25 \mathrm{mM}$, induced ICAM-1 expression to HAEC.

Our results further show that both SNO and LA block fructose-induced leukocyte adherence. The inhibitory effect of SNO on fructose-induced leukocyte adherence suggests that fructose induces depletion of endogenous NO reserve, a finding in agreement with those of Glushakova et al. (6), who showed that NO donors inhibit fructose-induced ICAM-1 expression in HAEC. NO is a potent anti-inflammatory molecule that inhibits the expression of endothelial cell adhesion molecules. In its absence, leukocytes bind to the surface receptors of adhesion molecules and begin the process of inflammation. The inhibitory effect of LA on fructose-induced leukocyte adherence may indicate that NO depletion results from fructose-induced ROS burden.

Our study cannot determine the mechanism with which fructose increases ROS levels. In all likelihood, fructose induces uric acid synthesis within the mesentery endothelial cells by dephosphorization of ATP, an obligatory step in the synthesis of fructose- 1 monophosphate. The resulting ADP is metabolized to uric acid and, in the process, ROS are generated. Fructose decreases intracellular ATP (6), and induces intracellular uric acid synthesis and ROS generation in human kidney proximal tubular cells (14). Uric acid reduces NO reserve in human umbilical vein endothelial cells (HUVEC) (15), stimulates vascular smooth muscle cell proliferation (16), and induces C-reactive protein expression in human vascular smooth muscle cells (17). Monosodium urate, in addition, promotes neutrophil adherence to osteoblast-like cells (18), rat intestinal epithelial cells, and HUVEC (19).

Alternatively, the carbonyl group of fructose may bind directly to the $-\mathrm{NH}_{2}$ group of the endothelial antioxidant enzymes protein, disabling their functional properties and depleting the antioxidant reserve (8). In our study, there were no statistically significant changes in wall shear rate within groups, so increased leukocyte adherence during fructose was independent of shear rate. Shear rate is an important determinant of leukocyte rolling and adherence. At low shear rate, leukocyte rolling and adherence increases. At high shear rate, leukocyte adherence is inhibited as shear rate induces release of NO. Studies both in animals (20) and in humans (21) have confirmed that $\mathrm{NO}$ is released from endothelial cells at high shear rate.

In contrast to fructose, dextrose did not induce significant leukocyte adherence in our study, in all likelihood due to the low concentrations used. In mice with type 1 diabetes, increased extracellular glucose $(30 \mathrm{mM})$ has been shown to rapidly stimulate intracellular ROS generation (22), and high glucose concentration also increases superoxide generation in HAEC (23). In normal subjects, acute hyperglycemia even in a concentration of approximately $15 \mathrm{mM}$ was shown to increase the cytokines IL-6, IL-18, and tumor necrosis factor- $\alpha$, an effect blocked by glutathione, suggesting an oxidative mechanism (24).

It is widely recognized that diabetes promotes ROS generation (25) and advanced glycation end products have been shown to selectively induce adhesion molecule expression and cytokine production in human peripheral blood mononuclear cells (26). To the best of our knowledge, however, a proinflammatory effect of high glucose on the mesenteric microcirculation has not been demonstrated.

In summary, fructose, but not dextrose, directly added to the rat mesentery induces marked and rapid inflammation. The effect of fructose may be mediated by an increase in oxidative burden, which in turn could decrease endogenous NO levels. This inflammatory effect of fructose is completely prevented by SNO and LA. The results of our study raise the possibility that formulas sweetened with sucrose or HFCS may adversely affect the intestinal microcirculation of the very small premature infant at risk of developing NEC. NEC occurs more frequently in infants fed formulas than in those fed human milk $(1,2)$, and inflammation plays a vital role in the pathogenesis of NEC (4). However, further studies are needed to confirm this possibility.

Study limitation: leukocytes adherent to the vascular endothelium were counted by a single experienced observer aware of the experimental conditions, whose intraobserver agreement was $97 \% \pm 0.04$.

\section{REFERENCES}

1. Schanler RJ, Shulman JR, Lau C 1999 Feedings strategies for premature infants: beneficial outcome of feeding fortified human milk versus preterm formula Pediatrics 103:1150-1157

2. Sisk PM, Lovelady CA, Dillard RG, Gruber KJ, O'Shea TM 2007 Early human milk feeding is associated with a lower risk of necrotizing enterocolitis in very low birth weight infants. J Perinatol 27:428-433

3. Meinzen-Derr J, Poindexter B, Wrage L, Morrow AL, Stoll B, Donovan EF 2009 Role of human milk in extremely low birth weight infants' risk of necrotizing enterocolitis or death. J Perinatol 29:57-62

4. Nanthakumar NN, Fusunyan RD, Sanderson I, Walker WA 2000 Inflammation in the developing human intestine: a possible pathophysiologic contribution to necrotizing enterocolitis. Proc Natl Acad Sci USA 97:6043-6048

5. Goldman AS, Chheda S, Garofalo R 1998 Evolution of immunologic functions of the mammary gland and the postnatal development of immunity. Pediatr Res 43:155-162

6. Glushakova O, Kosugi T, Roncal C, Wei M, Heinig M, Cirillo P, Sanchez-Losada L, Johnson RJ, Nagakawa T 2008 Fructose induces the inflammatory molecule ICAM-1 in endothelial cells. J Am Soc Nephrol 19:1712-1720

7. Gersch MS, Mu W, Cirillo P, Reungjui S, Zhang L, Roncal C, Sautin YY, Johnson RJ, Nagakawa T 2007 Fructose, but not dextrose, accelerates the progression of chronic kidney disease. Am J Physiol Renal Physiol 293:F1256-F1261

8. Zhao W, Devamanoharan PS, Varma SD 2000 Fructose induces deactivation of antioxidant enzymes: preventive effect of pyruvate. Free Radic Res 33:23-30

9. Wood JG, Johnson JS, Mattioli LF, Gonzalez NC 1999 Systemic hypoxia promotes leukocyte-endothelial cell adherence via reactive oxidant generation. J Appl Physiol $87: 1734-1740$

10. Steiner DR, Gonzalez NC, Wood JG 2003 Mast cells mediate the microvascular inflammatory response to systemic hypoxia. J Appl Physiol 94:325-334

11. Gonzalez NC, Allen J, Blanco VG, Schmidt EJ, van Rooijen N, Wood JG 2007 Alveolar macrophages are necessary for the systemic inflammation of acute alveolar hypoxia. J Appl Physiol 103:1386-1394

12. Gaby AR 2005 Adverse effects of dietary fructose. Altern Med Rev 10:294-306

13. MacDonald I, Keyser A, Pacy D 1978 Some effects, in man, of varying the load of glucose, sucrose, fructose, or sorbitol on various metabolites in blood. Am J Clin Nutr 31:1305-1311

14. Cirillo P, Gersch MS, Mu W, Scherer PM, Kim KM, Gesualdo L, Henderson GN, Johnson RJ, Sautin YY 2009 Ketohexokinase-dependent metabolism of fructose induces proinflammatory mediators in proximal tubular cells. J Am Soc Nephrol 20:545-553 
15. Khosla UM, Zharicov S, Finch JL, Nagakawa T, Roncal C, Mu W, Krotova K, Block ER, Prabhakar SJ, Johnson RJ 2005 Hyperuricemia induces endothelial cell dysfunction. Kidney Int 67:1739-1742

16. Rao GN, Corson MA, Berk BC 1991 Uric acid stimulates vascular smooth muscle cell proliferation by increasing platelet-derived growth factor A-chain expression. J Biol Chem 266:8604-8608

17. Kang DH, Park SK, Lee IK, Johnson RJ 2005 Uric acid-induced C-reactive protein expression: implication on cell proliferation and nitric oxide production of human vascular cells. J Am Soc Nephrol 16:3553-3562

18. Bouchard L, Naccache PH, Poubelle PE 2002 Promotion of neutrophil adherence to human osteoblasts by microcrystals and f-Met-Leu-Phe. Biochem Biophys Res Commun 296:759-764

19. Reinhardt PH, Naccache PH, Poubelle PE, de Medicis R, Kehrli ME, Kubes P 1996 Monosodium urate crystal promote neutrophil adhesion via a CD18-independent and selectin-independent mechanism. Am J Physiol 270:C31-C39

20. Lamontagne D, Ulrich P, Busse R 1992 Mechanical deformation of vessel wall and shear stress determine the basal release of endothelium derived relaxing factor in intact rabbit coronary vascular bed. Circ Res 70:123-130
21. Joannides R, Haefeli W, Linder L, Richard V, Bakkali EL, Thuillez C, Lüscher TF 1995 Nitric oxide is responsible for flow-dependent dilation of human peripheral conduit arteries in vivo. Circulation 91:1314-1319

22. Susztak K, Raf AC, Schiffer M, Bottinger EP 2006 Glucose-induced reactive oxygen species cause apoptosis of podocytes and podocyte depletion at the onset of diabetic nephropathy. Diabetes 55:225-233

23. Cosentino F, Hishikawa K, Katusic ZS, Luscher TF 1997 High glucose increases nitric oxide synthase expression and superoxide anion generation in human aortic endothelial cells. Circulation 96:25-28

24. Esposito K, Marfella R, Giugliano D 2003 Stress hyperglycemia, inflammation, and cardiovascular events. Diabetes Care 26:1650-1651

25. Brownlee M 2001 Biochemistry and molecular cell biology of diabetic complications. Nature 414:813-820

26. Takahashi HK, Mori S, Wake H, Liu K, Yoshino T, Ohashi K, Tanaka N, Shikata K, Makino H, Nishibori M 2009 Advanced glycation end products subspecies selectively induce adhesion molecule expression and cytokine production in human peripheral blood mononuclear cells. J Pharmacol Exp Ther 330:89-98 